\title{
INTRODUCCIÓN / INTRODUCTION
}




\section{LA ECONOMÍA POLÍTICA DE DANTE}

Frente a la actitud cada vez más indulgente del pensamiento teológico hacia la economía de mercado, que en su tiempo y en su ciudad, Florencia, había tenido un desarrollo espectacular, Dante consideró el afán de enriquecimiento no solo como un vicio subjetivo que degrada al ser humano, la avaricia, sino también como un factor de perversión social y política que degrada la humanidad en su conjunto. En algún que otro poeta de su tiempo también asoma esta problemática (por ejemplo, en Monte Andrea), pero en ninguno alcanza la amplitud de perspectivas que tiene en Dante. En efecto, la Divina Comedia se abre con una alegoría que denuncia justamente la perversión de la avidez: la loba que impide al protagonista huir de la «selva oscura» y que condena la humanidad a la barbarie (de la que Virgilio, en cuanto símbolo de civilización, acudirá a salvarlo).

Desde los poemas de argumento doctrinal escritos en Florencia, antes del año 1301, hasta sus últimas obras de la madurez, o sea el Paraíso y la Monarquía, la crítica de las primeras formas del capitalismo, que tenían en Florencia su centro de irradiación italiano y europeo, acompaña la reflexión política de Dante en cada momento de su desarrollo. Solo en años relativamente recientes la crítica ha aislado este aspecto fundamental del pensamiento del poeta, que destaca entre sus contemporáneos no solo por el radicalismo de su denuncia (justamente en Florencia empezaba el análisis de las nuevas formas de producción y circulación de la riqueza con el teólogo franciscano Pedro de Juan Olivi, autor de un tratado sobre los contratos, y maestro en el Estudio general de Santa Croce en los años 1287-89), sino por la agudeza de su análisis socioeconómico, que se refleja no solo en su poesía sino también en sus obras de pensamiento, como el Convivio, además de la Monarquía.

Uno de los momentos en que se vislumbró la centralidad de la economía política en la reflexión de Dante fue, en 2007, la celebración en S. Ulrich (Bozen-Bolzano) del coloquio ('ludoconvegno', según la terminología adoptada por sus participantes) sobre la canción Doglia mi reca ne lo core ardire, un texto en el que Dante despliega de forma monográfica su crítica de las formas 'modernas' de la economía. En aquella ocasión, y en el volumen que recogió las ponencias, afloraron algunos de los temas que resultarían de importancia capital en sucesivas aproximaciones al pensamiento económico de Dante ${ }^{1}$.

Después de unos años, animados por aquella experiencia, que abría un camino casi inexplorado hasta entonces, algunos de los participantes y otros colegas dantistas igualmente interesados en esta línea de investigación, decidimos dedicar una jornada

${ }^{1}$ Grupo Tenzone, Doglia mi reca ne lo core ardire, La biblioteca de Tenzone, Departamento de Filología Italiana UCM, Asociación Complutense de Dantología, Madrid, 2008. Contribuciones de Umberto Carpi, Domenico De Robertis, Violeta Díaz-Corralejo, Rosario Scrimieri, Carlos López Cortezo, Raffaele Pinto, Enrico Fenzi. 
de estudio y debate a dicha problemática, definiendo claramente su ámbito respeto a otros temas de interés filosófico y dantesco, es decir, La economía política de Dante.

El 16 febrero 2019, en la Librería 'La Central' de Barcelona, se celebró dicha jorna$\mathrm{da}$, en dos sesiones (presididas por Laura Cappuccio y Mathilde Brodu), y un debate final (moderado por Eduard Vilella y Rossend Arqués). Las ponencias fueron a cargo de Marco Romanelli, Donatella Stocchi-Perucchio, Marco Veglia, Augusto Nava, Mariano Pérez Carrasco, Raffaele Pinto, Juan Varela-Portas².

La percepción de los cambios que la nueva economía del dinero introducía en la sociedad de su tiempo, y la crítica de la economía protocapitalista, son los temas que, con diferentes matices, desarrollan los ensayos aquí recogidos. Augusto Nava Mora, en «Nobiltà, 'divizie' e riflesso in Dante parte de premisas filosóficas en sentido amplio (la óptica y los bestiarios) para llegar a los planteamientos más estrictamente sociopolíticos del poeta; Mariano Pérez Carrasco, en «Animal domesticum et civile: orden económico y orden político en Tomás de Aquino, Jacobo de Viterbo, Juan Quidort y Dante Alighieri», reconstruye las fuentes del pensamiento económico-político de su tiempo y el marco teórico en cuyo ámbito Dante desarrolla su crítica de la economía política; Raffaele Pinto, en «La lógica del mercado en las primeras reflexiones de Dante sobre la economía», se centra en los atisbos de crítica de la economía en los textos escritos en la etapa florentina; Marco Romanelli, en «Antiutilitarismo di Dante», invierte la visión regresiva o reaccionaria de Dante, dominante hasta ahora en los estudios dantescos, subrayando su visión de futuro; Donatella Stocchi Perucchio, «en Il maladetto fiore: Dante e il denaro alle origini del capitalismo», enfoca la polémica de Dante en contra de la economía y la ética del dinero a partir del pensamiento de Emmanuel Levinas y Michel Henry. Por último, Juan Varela-Portas, en «Nel mercato dei non saggi: lo sfruttamento della vita in dante (primi accenni per una ricerca)», considera los efectos, que Dante observa, padece y denuncia, de mercantilización no solo de la sociedad de su tiempo y del nuestro, sino del ser humano convertido en mercancía.

Gracias a la generosidad de la 'Revista Española de Filosofía Medieval' (y de las colegas Celia López Alcalde y Núria Sánchez Madrid), seis de las siete ponencias de aquel coloquio son ahora publicadas; el auspicio que acompaña esta publicación es que pueda ser semilla de futuros y más amplios estudios sobre una faceta de la obra de Dante que apunta, quizá más que cualquier otra, a los problemas más acuciantes de nuestra atormentada contemporaneidad ${ }^{3}$.

Raffaele Pinto

${ }^{2}$ Algunos de los ponentes (Nava, Pérez Carrasco, Pinto, Varela-Portas) participaron además en el 'Congresso dantesco internazionale 2019', organizado por la Universidad de Bologna y el Ayuntamiento de Rávena con un panel sobre Questioni di economia politica dantesca (31 de mayo 2019).

${ }^{3}$ Un signo ulterior del interés que este tema despierta en el ámbito de la dantística, es que el Forum de la revista estadounidense Dante Studies, que tendrá lugar en octubre de este año, será dedicado a este tema. 